\title{
Peningkatan Daya Saing Produk Dapur Kue Dzikra Melalui Redesain Logo Dan Kemasan Produk, Dan Pengembangan Pemasaran
}

\author{
Denny Astrie Anggraini' ${ }^{1)}$, Zayyinul Hayati Zen ${ }^{2)}$, Mentari Dwi Aristi ${ }^{3)}$ \\ ${ }^{1,2}$ Fakultas Teknik, Universitas Muhammadiyah Riau \\ 1,2email: dennyastrie@umri.ac.id, zayyinulhayati@umri.ac.id \\ ${ }^{3}$ Fakultas Ekonomi dan Bisnis, Universitas Muhammadiyah Riau \\ 3email: mentaridwi@umri.ac.id
}

\begin{abstract}
Dapur Kue Dzikra is a household business where one of the main products is chocolate pastries. However, in running its business there are several priority problems faced, namely the low competitiveness of Dapur Kue Dzikra products compared to other products, especially in souvenir outlets, due to unattractive packaging and brands that are not well known, packaging variations and limited product weight so that the selling price is high enough so it is less affordable for the buyer. Therefore, through this community service activity, brand branding is carried out by redesigning the logo and packaging using CorelDraw software, as well as increasing marketing through social media in order to increase its competitiveness and sales. The result of this community service activity was new logo and packaging from the Dapur Kue Dzikra that was more attractive, as well as an increase in sales from previously selling only $30 \mathrm{~kg}$ a month on average, now it has increased to $50 \mathrm{~kg} \mathrm{per}$ month with an estimated sales increase of $67 \%$.
\end{abstract}

Keywords: Competitiveness, Management, Marketing, Redesign

\begin{abstract}
Abstrak
Dapur Kue Dzikra adalah sebuah usaha rumah tangga yang salah satu produk utamanya adalah sus kering cokelat. Namun dalam menjalankan usahanya ada beberapa permasalahan prioritas yang dihadapi yaitu rendahnya daya saing produk Dapur Kue Dzikra dibandingkan dengan produk lain khususnya di gerai oleh-oleh, karena kemasan yang kurang menarik dan brand yang belum begitu dikenal luas, variasi kemasan dan berat produk yang terbatas sehingga harga jual yang cukup tinggi sehingga kurang terjangkau oleh pembeli. Oleh karena itu melalui kegiatan pengabdian ini dilakukan branding merk dengan redesain logo dan kemasan dengan menggunakan software coreldraw, serta peningkatan pemasaran melalui media social agar dapat meningkatkan daya saing dan penjualannya. Hasil dari kegiatan pengabdian ini adalah dihasilkannya logo dan kemasan baru dari Dapur Kue Dzikra yang lebih menarik, serta terjadi peningkatan penjualan dari sebelumnya yang rata-rata hanya menjual $30 \mathrm{~kg}$ dalam sebulan, saat ini sudah meningkat hingga $50 \mathrm{~kg}$ per bulannya dengan estimasi terjadi peningkatan penjualan sebesar $67 \%$.
\end{abstract}

Kata Kunci: Daya Saing, Manajemen, Pemasaran, Redesain

\section{PENDAHULUAN}

Dinas Koperasi dan Usaha Mikro Kecil dan Menengah Kota Pekanbaru menyebutkan berdasarkan data BRI ada sebanyak lebih kurang 13.531 Usaha
Mikro Kecil dan Menengah (UMKM) yang berada di Kota Pekanbaru. Dan saat ini pemerintah Kota Pekanbaru fokus melakukan pembinaan kepada usaha mikro karena sebagian besar dari pelaku usaha mikro tersebut masih sangat 
membutuhkan bantuan untuk memajukan usahanya. [1] Untuk membantu pemerintah Kota Pekanbaru dalam pembinaan terhadap usaha mikro, maka perlu dilakukan kegiatan pengabdian kepada masyarakat kepada salah satu usaha mikro yang dalam hal ini dilakukan pada sebuah industri rumah tangga yang ada di Kota Pekanbaru.

Industri Rumah Tangga menurut Badan Pusat Statistik adalah suatu kegiatan pengubahan barang dasar menjadi barang jadi atau setengah jadi, atau dari yang kurang nilainya menjadi menjadi barang yang lebih tinggi nilainya dengan maksud untuk dijual, dengan jumlah pekerja 1-4 orang. [2] Dapur Kue Dzikra merupakan salah satu industri rumah tangga yang mulai beroperasi sejak awal tahun 2012. Pada mulanya usaha ini merupakan usaha sampingan yang dibuat pemiliknya sembari bekerja di kantor dan berproduksi di rumah selepas bekerja. Namun pada tahun 2014 pemiliknya memutuskan berhenti bekerja dan menekuni usaha ini lebih maksimal.

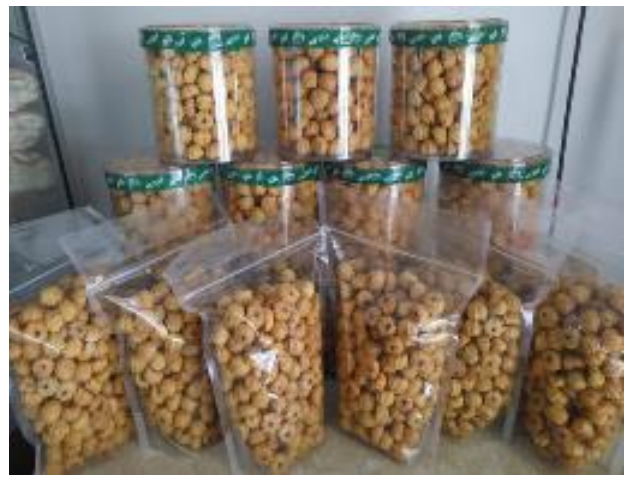

Gambar 1. Produk Kue Sus Kering Cokelat \& Kemasan saat ini.

Salah satu produk yang dihasilkan Dapur Kue Dzikra adalah Kue Sus Kering Cokelat seperti pada gambar 1. Produksi di Dapur Kue Dzikra hampir setiap hari dilakukan, rata-rata dalam seminggu minimal dilakukan 2 kali pembuatan kue sus kering diselingi dengan pembuatan produk dan pesanan lainnya dengan menggunakan peralatan produksi sederhana seperti pada gambar 2 .
Saat ini produk utama tersebut dipasarkan langsung kepada konsumen yang dikenal oleh pemilik, selain itu produk ini juga dijual pada reseller yang ada di kota Pekanbaru maupun di luar kota untuk kemudian mereka jual kembali dengan menggunakan merk mereka sendiri.

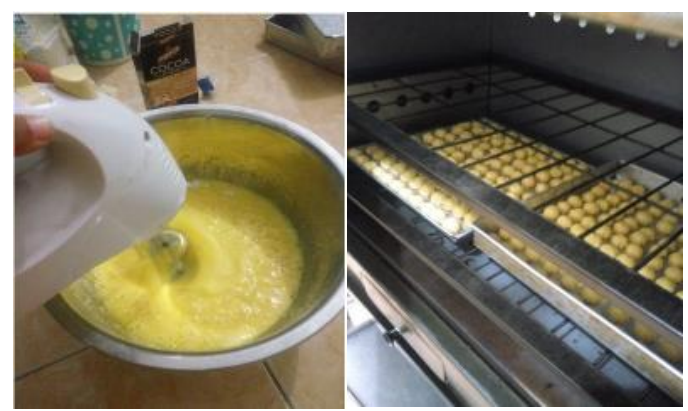

Gambar 2. Fasilitas Produksi

Hal ini tentu saja mengakibatkan brand Dapur Kue Dzikra tidak terlalu dikenal padahal produk tersebut adalah produk unggulan yang harusnya bisa menjadi ikon bagi Dapur Kue Dzikra. Selain itu kemasan produk khususnya sus kering hanya terdiri dari dua variasi saja yaitu dalam toples plastik dengan berat 600 gram netto yang dijual dengan harga $\mathrm{Rp}$ 75.000. Juga dalam kemasan plastik dengan berat 500 gram dan harga jual Rp. 60.000 , sehingga dirasa cukup mahal oleh pembeli. Produk utama Dapur Kue Dzikra ini belum dijual di gerai-gerai oleh-oleh Pekanbaru ataupun di minimarket karena berdasarkan pengalaman sebelumnya produk yang dititip di gerai ini tidak begitu laku dan kalah saing dengan produk lainnya yang sangat banyak jenisnya dan harga lebih murah. Logo sus kering cokletas yang digunakan saat ini seperti pada gambar 3 . 


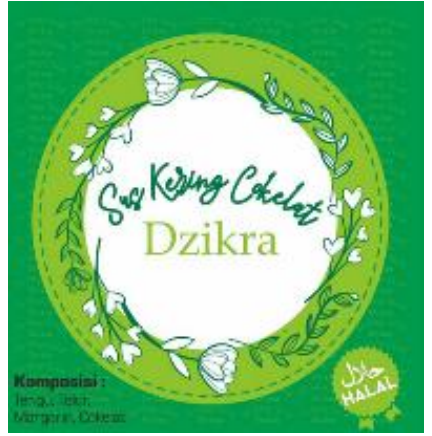

Gambar 3. Sticker logo kemasan yang digunakan di awal

Berdasarkan uraian di atas maka untuk dapat meningkatkan daya saing perlu dieliminasi berbagai permasalahan yang dihadapi oleh mitra melalui kegiatan pengabdian kepada masyarakat ini dengan melakukan branding merk berupa redesain logo dan kemasan, serta peningkatan pemasaran melalui media social dan gerai agar dapat meningkatkan daya saing dan penjualannya.

\section{Tinjauan Pustaka}

Desain kemasan menarik dan unik pasti punya semacam karakter yang bisa membedakan dengan produk lainnya. Adapun fungsi desain kemasan yang menarik adalah merefleksikan produk itu sendiri dan karakter bisnis yang dijalani. Bagi pelaku bisnis yang sudah berpengalaman, tentu hal ini sangat diperhatikan karena dapat membantu proses pemasaran.

Beberapa fungsi desain kemasan produk yang menarik, antara lain :

1. Membantu pemasaran karena dalam desain kemasan tersebut tercantum informasi penting seperti merek bisnis, jenis produk, penjelasan produk, expire date, kandungan gizi, serta alamat dan keterangan produsen.

2. Meningkatkan kualitas serta brand awereness produk tersebut karena makin dikenal sekaligus dipercaya konsumen dan calon konsumen baru.

3. Menjaga kualitas barang di dalamnya seperti makanan tetap aman, pakaian agar tidak rusak, alat elektronik tetap terjamin dan bisa digunakan. [3]

Menurut Nillson \& Ostrom (2005), variable desain kemasan terdiri dari 3 dimensi, yaitu: desain grafis, struktur desain, dan informasi produk. [4]

Selain kemasan, hal pendukung dari sebuah produk adalah logo. Kategori tanda yang dikemukakan oleh Peirce (1839-1914), bahwa logo merupakan sebuah ikon daripada suatu industri yang diwakilinya. Ikon sebagai sebuah gambar yang dihasilkan oleh manusia dapat merujuk kepada sesuatu yang diwakilinya. Ikon dapat menjadi suatu identiti pengenalan bagi objeknya, dalam hal ini bererti logo dapat menjadi identiti khas bagi industri yang diwakilinya di mana ia direka bentuk untuk mewakili visi, misi, dan identiti industri yang diinginkan. [5]

\section{METODE PENGABDIAN}

Tahapan dalam pelaksanaan kegiatan antara lain :

a. Sosialisasi Program

Pelaksanaan kegiatan diawali dengan sosialisasi rencana kegiatan kepada mitra mengenai lingkup program yang akan dilaksanakan, waktu pelaksanaan kegiatan, tahapan kegiatan, pendampingan, evaluasi kegiatan dan monitoring.

b. Pendampingan kegiatan

Kegiatan Pendampingan dilakukan sesuai kebutuhan dan dilakukan pada semua tahapan kegiatan, mulai dari perancangan logo dan desain kemasan produk yang bernilai jual hingga hingga pengembangan pemasaran produk.

c. Evaluasi kegiatan

Evaluasi dilakukan dalam upaya memaksimalkan hasil kegiatan sesuai dengan target yang sudah ditentukan. Evaluasi dilakukan terhadap semua bentuk kegiatan yang dilakukan dalam semua tahap kegiatan. Apabila terdapat kegiatan yang memberikan hasil yang tidak maksimal maka dilakukan upaya penyempurnaan kegiatan tersebut. 


\section{d. Penyusunan Laporan Pelaksanaan Kegiatan}

Kegiatan ini mulai dilakukan pada 1 Desember 2020 hingga 1 April 2021, karena masih dalam kondisi pandemic Covid-19 maka kegiatan umumnya dilakukan secara daring melalui media social. Namun untuk diskusi terkait desain logo dan kemasan dilakukan secara langsung di tempat mitra.

\section{HASIL DAN PEMBAHASAN}

Pelaksanaan kegiatan diawali dengan sosialisasi rencana kegiatan kepada mitra mengenai lingkup program yang akan dilaksanakan serta waktu pelaksanaan kegiatan. Kegiatan yang dilakukan untuk meningkatkan daya saing produk Dapur Kue Dzikra dilakukan melalui survey awal berbagai bentuk kemasan yang akan dipilih dan tepat bagi produk Kue Sus Kering Cokelat Dapur Kue Dzikra. Beberapa rencana pilihan bentuk kemasan yang akan digunakan seperti pada gambar 4 berikut ini.

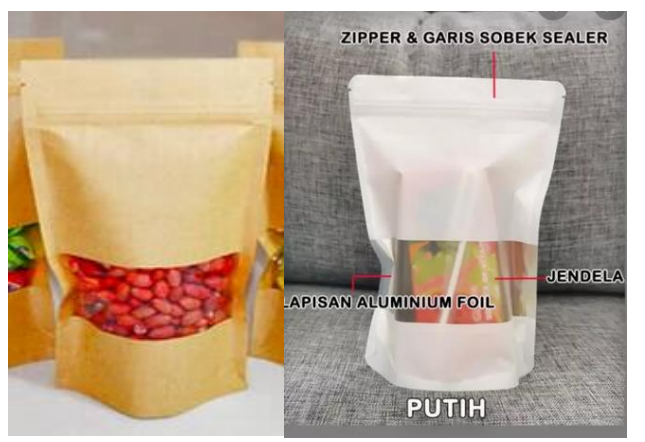

(a)

(b)

Gambar 4. Pilihan Bentuk Kemasan

Kemasan (a) merupakan kemasan berbahan kertas menggunakan zipper dan garis sobek dengan jendela plastik transparan sehingga produk terlihat dari luar. Sedangkan kemasan (b) adalah kemasan berbahan plastik dove dengan lapisan aluminium menggunakan zipper dan garis sobek dengan jendela plastik transparan. Dari alternatif yang ada, maka bentuk kemasan (b) dipilih karena menggunakan bahan plastik dove yang dilapisi aluminium sehingga lebih kuat dan tidak mudah sobek dibandingkan dengan alternatif (a).

Setelah kemasan ditentukan maka selanjutnya dilakukan perancangan logo dan desain bentuk kemasan dengan memperhatikan teori dalam perancangan kemasan dan diskusi dengan pemilik Dapur Kue Dzikra serta desainer, maka diperoleh rancangan logo dan desain kemasan seperti pada gambar 5 dan gambar 6 berikut ini.

Logo yang dibuat menunjukkan identitas Dapur Kue Dzikra yang umumnya menghasilkan produk olahan makanan yang diharapkan menjadi pilihan utama oleh konsumen.

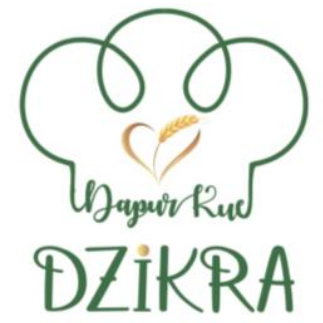

Gambar 5. Hasil Desain Logo

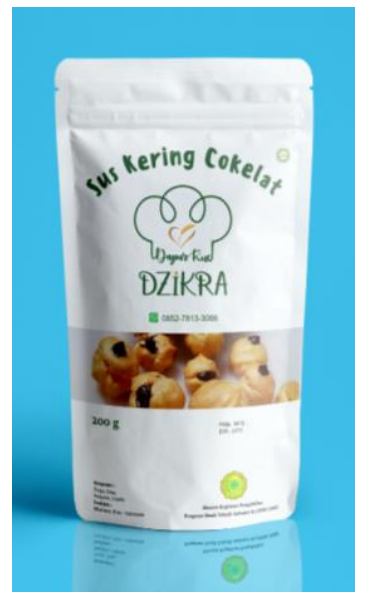

\section{Gambar 6. Hasil Desain Kemasan}

Pada kemasan dicantumkan nama merk dan logo yang mencirikan produk. Warna yang dipilih warna putih karena memiliki arti bersih dan steril sesuai produk yang dihasilkan. Huruf yang digunakan juga huruf yang mudah dibaca namun tetap menarik. Dengan adanya jendela plastik transparan ini produk dengan jelas dapat 
terlihat. Selain itu pada kemasan juga terdapat informasi mengenai komposisi produk, masa kadaluarsa, ukuran berat, dan nomor kontak agar konsumen dapat dengan mudah melakukan pemesanan ulang.

Setelah dilakukan perancangan kemasan, maka tahap selanjutnya adalah proses pemesanan kemasan. Setelah kemasan diterima, selanjutnya dilakukan proses pengemasan seperti pada gambar 7 .

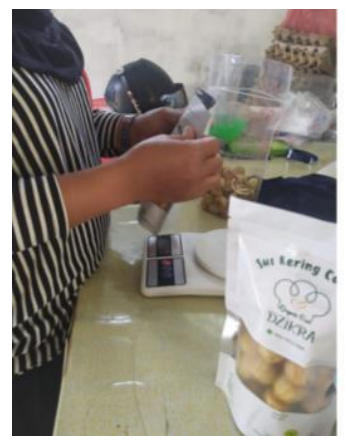

Gambar 7. Proses Pengemasan Produk

Dengan kemasan baru ini produk terlihat lebih menarik dan dapat dijual dengan harga lebih tinggi, sehingga produk ini dapat lebih mudah dipasarkan. Kemasan yang disediakan ini berukuran 22 $\mathrm{x} 14 \mathrm{~cm}$, dan berat bersih produk yang diisi lebih kurang 200gr. Langkah selanjutnya adalah pemotretan produk untuk memudahkan pemasaran. Produk jadi kemasan seperti terlihat pada gambar 8 berikut ini.

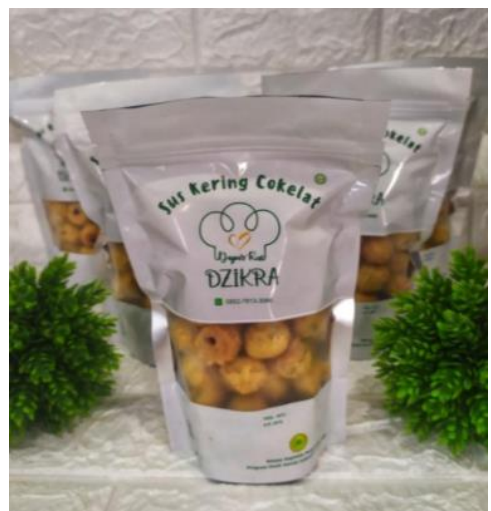

Gambar 8. Kue Sus Kering Cokelat dengan Kemasan Baru
Produk dengan kemasan baru ini beratnya 200 gr dan dijual kepada konsumen dengan harga Rp. 25.000,-. Dengan kemasan baru ini produk menjadi lebih mudah diterima oleh konsumen dan dapat dengan mudah bersaing apabila dipasarkan melalui media sosial dan jika diletakkan di pusat atau gerai oleh-oleh yang ada di Pekanbaru. Saat ini produk Sus Kering Cokelat sudah dijual di salah satu gerai oleh-oleh yang ada di Pekanbaru yaitu gerai Mangan (gambar 9) dan sudah merestok sebanyak 2 kali dalam rentang waktu 3 bulan penjualan. Dengan perubahan kemasan ini, permintaan terhadap produk semakin meningkat. Ratarata penjualan sebelum menggunakan kemasan ini adalah $30 \mathrm{~kg}$ per bulan, namun saat ini penjualan mencapai $50 \mathrm{~kg}$ bahkan lebih setiap bulannya. Hal ini menunjukkan terjadinya peningkatan penjualan lebih kurang $67 \%$ dari sebelum penggunakan kemasan baru.

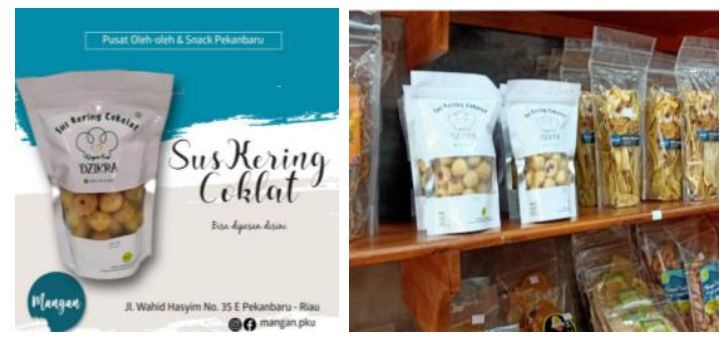

Gambar 9. Kue Sus Kering Cokelat di Gerai Oleh-Oleh

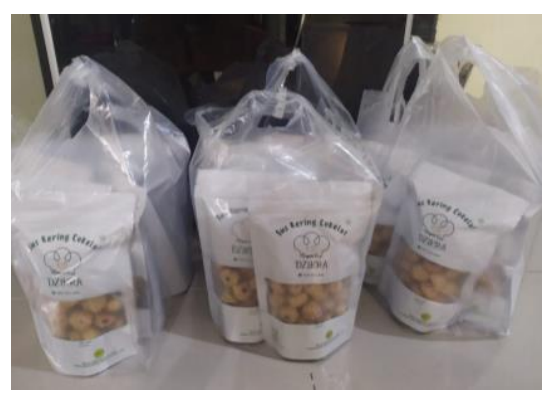

Gambar 10. Peningkatan Permintaan Kue Sus Kering Cokelat

\section{SIMPULAN}

1. Branding merk berupa redesain logo dan kemasan sebelum dan sesudah kegiatan pengabdian masyarakat sebagai berikut : 


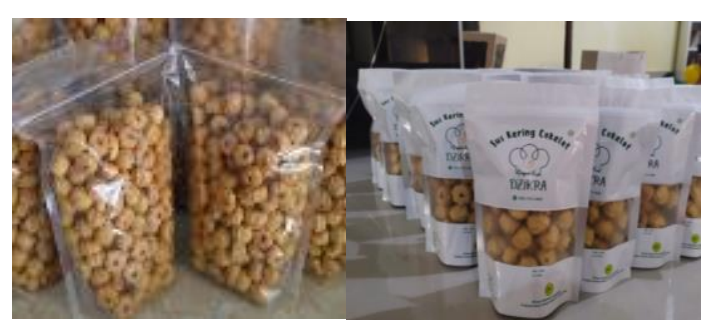

Gambar 11. Kemasan Sebelum dan Sesudah Pengabdian

2. Peningkatan pemasaran dilakukan melalui media sosial dan gerai oleh-oleh yang ada di Pekanbaru, terbukti dengan penjualan yang rata-rata meningkat hingga $67 \%$ setiap bulannya.

\section{UCAPAN TERIMAKASIH}

Ucapan terima kasih diberikan kepada Terimakasih kepada Lembaga Penelitian dan Pengabdian kepada Masyarakat Universitas Muhammadiyah Riau yang telah mendanai kegiatan pengabdian kepada masyarakat ini. Kemudian ucapan terimakasih juga kepada Mitra "Dapur Kue Dzikra" atas kerjasamanya.

\section{DAFTAR PUSTAKA}

[1] http://pekanbaru.go.id/p/news/diskopumkm-pekanbaru-fokus-bina-usahamikro, diakses pada 30 Agustus 2019

[2] Joesyiana, Kiki. (2017). Strategi Pengembangan Industri Rumah Tangga Di Kota Pekanbaru (Studi Kasus Usaha Tas Rajut Industri Pengolahan Kreatifitas Tali Kur). Jurnal Valuta, 3, 159-171

[3] Hendrayani, Yani. \& Manihuruk, Hermina. (2020). Redesain Kemasan Dalam Meningkatkan Brand Awarness Produk Unggulan UKM Cilodong Berkarya. Jurnal Bakti Masyarakat Indonesia, 3, 212-220.

[4] Nugroho, S., Darminto, P., Ulkhaq, M. \& Permadi,T. (2017). Redesain Kemasan Makanan Ringan Olahan Pada UMKM Center jawa Tengah
Dengan Metode Kansei Engineering. Jurnal Performa, 16, 77-86.

[5] Wahmuda, Faza. \& Hidayat, M. (2020). Redesain Logo dan Media Promosi Sebagai Citra Produk Makanan Ringan UKM Benok. Andharupa : Jurnal Desain Komunikasi, Visual dan Multimedia, 6, 147-159. 